\title{
Development of a practical guide for the early recognition for malignant melanoma of the foot and nail unit
}

Ivan R Bristow ${ }^{1 *}$, David AR de Berker ${ }^{2}$

\begin{abstract}
Background: Malignant melanoma is a rare but potentially lethal form of cancer which may arise on the foot. Evidence suggests that due to misdiagnosis and later recognition, foot melanoma has a poorer prognosis than cutaneous melanoma elsewhere.
\end{abstract}

Methods: A panel of experts representing podiatry and dermatologists with a special interest in skin oncology was assembled to review the literature and clinical evidence to develop a clinical guide for the early recognition of plantar and nail unit melanoma.

Results: A systematic review of the literature revealed little high quality data to inform the guide. However a significant number of case reports and series were available for analysis. From these, the salient features were collated and summarised into the guide. Based on these features a new acronym "CUBED" for foot melanoma was drafted and incorporated in the guide.

Conclusions: The use of this guide may help clinicians in their assessment of suspicious lesions on the foot (including the nail unit). Earlier detection of suspicious pedal lesions may facilitate earlier referral for expert assessment and definitive diagnosis. The guide is currently being field tested amongst practitioners.

\section{Introduction}

The incidence of malignant melanoma (MM) continues to rise in the UK and Europe [1]. Despite being an uncommon form of skin cancer it is responsible for the majority of skin cancer deaths [2]. Health education campaigns have increased public awareness of the problem and there is evidence to show that sectors of the population are presenting earlier with their suspicious skin lesions [3-5]. Despite these improvements, mortality and morbidity still remains high, particularly within subsets of the population such as older adults [6,7], males [8-10], the less affluent [11] and less well educated $[12,13]$.

Around $3-15 \%$ of all cutaneous MM arise on the foot $[14,15]$. However, MM arising on the foot holds a poorer prognosis than melanoma elsewhere $[16,17]$. The reasons for this are not certain, but there are several

\footnotetext{
* Correspondence: ib@soton.ac.uk

'School of Health Sciences, University of Southampton, Highfield,

Southampton, SO17 1BJ, UK

Full list of author information is available at the end of the article
}

possible explanations. The basic prognostic indicator for melanoma at all sites is the thickness of the tumour as measured under the microscope in millimetres. This is known as the Breslow thickness. The greater the thickness of the tumour, the more likely that the patient will die in the following five years. Thick lesions on the hands and feet have been shown to have a worse prognosis than tumours of a similar thickness elsewhere [18]. Some investigators have attributed this to pedal lesions being more aggressive in nature [19], though others have disputed this as a statistical anomaly due to the small numbers involved [20]. Other authors have suggested that the Breslow thickness grading in plantar and nail melanoma is often more difficult to determine or inconclusive [21].

Delay in diagnosis is a further factor, where the length of history of the melanoma has a correlation with Breslow thickness and hence deterioration of prognosis. Foot lesions are often detected by health care practitioners later than lesions elsewhere. A tumour on the face is more likely to result in prompt action by the
C Biomed Central

() 2010 Bristow and de Berker; licensee BioMed Central Ltd. This is an Open Access article distributed under the terms of the Creative Commons Attribution License (http://creativecommons.org/licenses/by/2.0), which permits unrestricted use, distribution, and reproduction in any medium, provided the original work is properly cited. 
patient and practitioner than one on the foot. Furthermore, lesions between the toes, beneath the nail or on the sole are further concealed. As a result, delayed presentation results in thicker, more advanced tumours [22-24]. Secondly, foot melanoma, possibly because of its rarity, is frequently misdiagnosed as a more common foot disorder such as tinea pedis [25-29], onychomycosis [30], warts [31-36], haematoma [25,37-39], paronychia [40], ingrowing toe nail [41-43], bacterial infection [44], ischaemia or necrosis $[14,40]$, blisters, ganglions, callus [42], benign tumours [45,46] and ulceration [47-54]. Misdiagnosis rate for foot lesions have been reported to be between $25 \%-66 \%$ [14,25,40] compared with much lower rates of around $12-16 \%$ for melanoma in other anatomical locations $[27,55,56]$. This is probably a reflection of the fact that patients do not initially suspect the diagnosis of skin cancer at these sites and therefore consult healthcare professionals other than dermatologists with lesions who may not be so aware of the possibility of a malignant lesion.

The priority of skin cancer has been highlighted by the Government in its strategy to reform Cancer Services in the UK [57]. Through the "SUNSMART" campaign http://www.sunsmart.org.uk, the government aims to increase public awareness of the disease and stress the importance of seeking professional opinion. On the professional side, guidelines issued from the National Institute for Clinical Excellence (NICE) stress the importance of health care professionals being aware of the modified 7-point checklist [58] for assessment of pigmented skin lesions and where any patient presenting with a skin lesions should be referred to a specialist skin care team [59]. Some guidelines have been published in the UK and Australasia, specifically for medical practitioners for melanoma [60-62] but none are known to exist specifically for lesions arising on the foot. A review of cases in one district [25], demonstrated a significant number of melanoma cases were seen by foot specialists prior to diagnosis.

The need for greater awareness to permit earlier recognition of foot melanoma amongst health care practitioners has been expressed [22]. In turn this could lead to faster recognition, referral and diagnosis. Authors have commented that the traditional melanoma screening algorithms, the ABCDE system \& 7-point checklist may be less effective when applied to the foot $[25,40,63]$. The plantar surface with its thickened epidermis is subject to trauma and hyperkeratotic changes which are not found elsewhere and may disguise critical signs.

In conjunction with the Society of Chiropodists and Podiatrists (Faculty of Podiatric Medicine and General Practice), a panel was convened to draft guidance for its members to raise awareness of the condition. The guide development group consisted of a team consisting of a podiatrist and four dermatologists each with a special interest in skin cancer.

\section{Methods}

Initially the panel compiled a list of clinical questions relevant to the topic of foot and nail melanoma to help inform a search strategy. A literature search was undertaken using the National Library of Medicine (NLM) PubMed database to identify literature on foot and nail melanoma. A range of search terms was devised (see below):

1: foot OR feet OR "lower extremity" OR acral OR plantar OR nail OR leg OR ankle OR sub-ungual (233864)

2: melanoma (74768)

3: Diagn* OR recogn*OR screen* (2518063)

\section{Limits: English Language \& Human \\ Total of combination: $\mathbf{8 4 3}$}

From the initial sweep $(n=843)$, papers whose primary focus fell outside of the topic (i.e. did not discuss recognition, detection, diagnosis and features) were discarded, typically these included papers solely discussing prognosis and survival, surgery and management. Papers which also made brief mention of the foot with no subset analyses were excluded. The remaining papers were reviewed, by both authors, using guidance as outlined by the National Institute for Clinical Excellence [64](Table 1). Papers were classified according to their level of evidence and reviewed for content. In addition, a separate search was undertaken to establish if previous, relevant guidelines had been published elsewhere.

\section{Results}

The review of the literature identified a lack of high level evidence to inform the development of a guide.

\begin{tabular}{|c|c|}
\hline $\begin{array}{l}\text { Level of } \\
\text { Evidence }\end{array}$ & Type of evidence \\
\hline $1^{* *}$ & $\begin{array}{l}\text { High quality meta-analyses, or systematic reviews of } \\
\text { randomised controlled trials (RCTs). }\end{array}$ \\
\hline $1^{*}$ & $\begin{array}{l}\text { Well conducted meta-analyses, systematic reviews of } \\
\text { RCTs. }\end{array}$ \\
\hline $1-$ & $\begin{array}{c}\text { Meta-analyses, systematic reviews of RCTs or RCTs with } \\
\text { a high risk of bias. }\end{array}$ \\
\hline $2^{* *}$ & $\begin{array}{l}\text { High quality systematic reviews of cohort or case- } \\
\text { control studies. High quality cohort or case-control } \\
\text { studies with a low risk of confounding bias or chance. }\end{array}$ \\
\hline $2^{*}$ & $\begin{array}{l}\text { Well conducted case-control or cohort studies with a } \\
\text { low risk of confounding bias or chance. }\end{array}$ \\
\hline 2 & $\begin{array}{l}\text { Case-control or cohort studies with a high risk of } \\
\text { confounding bias or chance. }\end{array}$ \\
\hline 3 & Non-analytic studies (case reports, case series). \\
\hline 4 & Expert opinion, formal consensus. \\
\hline
\end{tabular}


Based on the NICE grading system, a small number of case-control studies were identified examining aetiology, incidence and clinical features (level 2). Most of the published literature pertaining to foot melanoma was ranked at level 3 , being predominantly case reports $(n=$ $44)$, literature reviews/discussions $(\mathrm{n}=21)$ and case series $(\mathrm{n}=14)$ of foot melanoma. On this basis, it was accepted that the paper would be drafted on the strength of the available evidence with informed consensus methods amongst the group to develop guidance.

All case reports and case series were examined by the authors. The hierarchy of evidence places such literature at a low level, just above that of medical opinion. However, case studies have the capacity to report rare diseases or the manifestations of disease which can be a useful learning tool in medical education [65]. The authors reviewed these papers looking for common themes, key messages and learning points. The focus of such papers was often around misdiagnosis, delay and deterioration of the lesion. Based on this data, a new acronym was proposed specific for foot melanoma. An existing $A B C D E$ acronym was included for nail melanoma [66].

Subsequent to drafting the paper was reviewed by the panel. External reviewers were identified. These included practising podiatrists and chiropodists, a general practitioner, a diabetologist and other specialists involved in foot care. To facilitate a simple and rapid feedback mechanism, participants were electronically e-mailed a copy of the draft guidelines and then asked to respond by an online feedback website. Respondents were asked to comment on the draft including content, readability and clarity of the draft document. Following the consultation, amendments were made and the guidelines have been reviewed and have been submitted for publication.

\section{Conclusions}

The development and use of a guide may help clinicians in their assessment of suspicious lesions on the foot (including the nail unit). Earlier detection of suspicious pedal lesions may facilitate earlier referral for expert assessment and definitive diagnosis. The guide has been tested amongst practitioners and has been submitted for publication.

\footnotetext{
Acknowledgements

The melanoma working group consisted of:

Ivan Bristow, Lecturer, School of Health Sciences, University of Southampton, UK

David de Berker, Consultant Dermatologist, Bristol Royal Infirmary, Bristol, UK Katharine Acland, Consultant Dermatologist, St John's Institute of Dermatology, St Thomas' Hospital London, UK

Richard Turner, Consultant Dermatologist, Churchill Hospital, Oxford Radcliffe Hospitals, Oxford, UK

Jonathan Bowling, Dermatologist, Churchill Hospital, Oxford Radcliffe

Hospitals, Oxford, UK
}

The authors would like to thank colleagues who reviewed the drafts and for their detailed feedback including Laurie King and Alistair McInnes.

\section{Author details}

${ }^{1}$ School of Health Sciences, University of Southampton, Highfield, Southampton, SO17 1BJ, UK. ${ }^{2}$ Bristol Dermatology Centre, Bristol Royal Infirmary, Bristol, BS2 8HW, UK.

\section{Authors' contributions}

IB was responsible for the original drafting of this paper. Subsequent revisions and amendments were made jointly by DB and IB. Both authors have read and approved the final manuscript.

\section{Competing interests}

The authors declare that they have no competing interests.

Received: 7 June 2010 Accepted: 28 September 2010

Published: 28 September 2010

\section{References}

1. Karim-Kos HE, de Vries E, Soerjomataram I, Lemmens V, Siesling S, Coebergh JW: Recent trends of cancer in Europe: A combined approach of incidence, survival and mortality for 17 cancer sites since the 1990s. Eur J Cancer 2008, 44:1345-1389.

2. UK Skin Cancer mortality statistics. [http://info.cancerresearchuk.org/ cancerstats/types/skin/mortality/].

3. Buettner P, Leiter U, Eigentler T, Garbe C: Development of prognostic factors and survival in cutaneous melanoma over 25 years. Cancer 2005, 103:616-624

4. Harman KE, Fuller LC, Salisbury JR, Higgins EM, du Vivier AW: Trends in the presentation of cutaneous malignant melanoma over three decades at King's College Hospital, London. Clin Exp Dermatol 2004, 29:563-566.

5. MacKie RM, Hole D: Audit of public education campaign to encourage earlier detection of malignant melanoma. BMJ 1992, 304:1012-1015.

6. Payette MJ, Katz M, Grant-Kels JM: Melanoma prognostic factors found in the dermatopathology report. Clin Dermatol 2009, 27:53-74.

7. Rex J, Paradelo C, Mangas C, Hilari JM, Fernandez-Figueras MT, Ferrandiz C: Management of primary cutaneous melanoma of the hands and feet: a clinicoprognostic study. Dermatol Surg 2009, 35:1505-1513.

8. Downing A, Yu XQ, Newton-Bishop J, Forman D: Trends in prognostic factors and survival from cutaneous melanoma in Yorkshire, UK and New South Wales, Australia between 1993 and 2003. Int I Cancer 2008, 123:861-866.

9. Phan A, Touzet S, Dalle S, Ronger-Savle S, Balme B, Thomas L: Acral lentiginous melanoma: a clinicoprognostic study of 126 cases. $\mathrm{Br} J$ Dermatol 2006, 155:561-569.

10. Swetter SM, Johnson TM, Miller DR, Layton CJ, Brooks KR, Geller AC: Melanoma in Middle-aged and Older Men: A Multi-institutional Survey Study of Factors Related to Tumor Thickness. Arch Dermatol 2009, 145:397-404.

11. Ortiz CA, Goodwin JS, Freeman JL: The effect of socioeconomic factors on incidence, stage at diagnosis and survival of cutaneous melanoma. Med Sci Monit 2005, 11:RA163-172.

12. Baumert J, Plewig G, Volkenandt M, Schmid-Wendtner MH: Factors associated with a high tumour thickness in patients with melanoma. $\mathrm{Br} J$ Dermatol 2007, 156:938-944.

13. Schmid-Wendtner MH, Baumert J, Stange J, Volkenandt M: Delay in the diagnosis of cutaneous melanoma: an analysis of 233 patients. Melanoma Res 2002, 12:389-394.

14. Bennett DR, Wasson D, MacArthur JD, McMillen MA: The effect of misdiagnosis and delay in diagnosis on clinical outcome in melanomas of the foot. J Am Coll Surg 1994, 179:279-284.

15. Soong SJ, Shaw HM, Balch CM, MCCarthy WH, Urist MM, Lee JY: Predicting survival and recurrence in localized melanoma: a multivariate approach. World J Surg 1992, 16:191-195.

16. Dwyer PK, Mackie RM, Watt DC, Aitchison TC: Plantar malignant melanoma in a white Caucasian population. Br J Dermatol 1993, 128:115-120.

17. Hsueh E, Lucci A, Qi K, Morton D: Survival of patients with mealnoma of the lower extremity decreases with distance from the trunk. Cancer Causes Control 1998, 85:383-388. 
18. Day CL, Sober AJ, Kopf AW, Lew RA, Mihm MC, Golomb FM, Hennessey P, Harris MN, Gumport SL, Raker JW, et al: A prognostic model for clinical stage I melanoma of the lower extremity. Location on foot as independent risk factor for recurrent disease. Surgery 1981, 89:599-603.

19. Talley LI, Soong S-j, Harrison RA, McCarthy WH, Urist MM, Balch CM: Clinical Outcomes of Localized Melanoma of the Foot: A Case-Control Study. J Clin Epidemiol 1998, 51:853-857.

20. Barnes B, Seigler H, Saxby T, Kocher M, Harrelson J: Melanoma of the foot. J Bone Joint Surg Am 1994, 76:892-898.

21. Dawber RP, Colver GB: The spectrum of malignant melanoma of the nail apparatus. Semin Dermatol 1991, 10:82-87

22. Franke W, Neumann NJ, Ruzicka T, Schulte K: Plantar malignant melanoma - a challenge for early recognition. Melanoma Res 2000, 10:571-576.

23. Hemo Y, Gutman M, Klausner JM: Anatomic site of primary melanoma is associated with depth of invasion. Arch Surg 1999, 134:148-150.

24. Nagore E, Oliver V, Moreno-Picot S, Fortea JM: Primary cutaneous melanoma in hidden sites is associated with thicker tumours - a study of 829 patients. Eur I Cancer 2001, 37:79-82.

25. Bristow I, Acland K: Acral lentiginous melanoma of the foot: a review of 27 cases. J Foot Ankle Res 2008, 1:11.

26. Dainichi T, Kobayashi C, Fujita S, Shiramizu K, Ishiko T, Kiryu H, Urabe K, Tsuneyoshi M, Furue M: Interdigital amelanotic spindle-cell melanoma mimicking an inflammatory process due to dermatophytosis. J Dermatol 2007, 34:716-719.

27. Dunkley MP, Morris AM: Cutaneous malignant melanoma: audit of the diagnostic process. Ann R Coll Surg Engl 1991, 73:248-252.

28. Serarslan G, Akcaly C, Atik E: Acral lentiginous melanoma misdiagnosed as tinea pedis: a case report. Int I Dermatol 2004, 43:37-38.

29. Waddington $A M$, Hogg L: The surgical management of a subungual acral malignant melanoma:a case presentation and review of the literature. Brit J Pod 2007, 10:166-170.

30. De Giorgi V, Sestini S, Massi D, Panelos J, Papi F, Dini M, Lotti T: Subungual melanoma: a particularly invasive "onychomycosis". J Am Geriatr Soc 2007, 55:2094-2096.

31. Arroyo MP, Chu DH, Mobini N, Park HS: Verrucous plaque on the foot. J Cutan Pathol 2004, 31:271-273.

32. De Giorgi V, Massi D: Images in clinical medicine. Plantar melanoma-a false vegetant wart. N Engl J Med 2006, 355:e13.

33. Knedgen J, Colburn M, Cooke R, Silvani S: Digital occurrence of nodular malignant melanoma. J Am Podiatr Med Assoc 1997, 87:178-182.

34. McBurney El, Herron CB: Melanoma mimicking plantar wart. J Am Acad Dermatol 1979, 1:144-146.

35. Rosen T: Acral lentigious melanoma misdiagnosed as verruca plantaris: a case report. Dermatol Online J 2006, 12.

36. Virgili A, Corazza M: Guess what! Metastatic malignant melanoma of the leg from a warty acral amelanotic malignant melanoma. Eur J Dermatol 2001, 11:591-592.

37. Fountain JA: Recognition of subungual hematoma as an imitator of subungual melanoma. J Am Acad Dermatol 1990, 23:773-774.

38. Hussain W, Desai S, Fitzgerald D: An (un)lucky blow to the nail? Clin Exp Dermatol 2009, 34:446-447.

39. Yasuoka, Ueda, Ohgami, Hayashi, Ichihashi : Amelanotic acral lentiginous malignant melanoma. Br J Dermatol 1999, 141:370-372.

40. Metzger S, Ellwanger U, Stroebel W, Schiebel U, Rassner G, Fierlbeck G: Extent and consequences of physician delay in the diagnosis of acral melanoma. Melanoma Res 1998, 8:181-186.

41. Lemont H, Brady J: Amelanotic Melanoma Masquerading as an Ingrown Toenail. J Am Podiatr Med Assoc 2002, 92:306-307.

42. Soon SL, Solomon AR, Papadopoulos D, Murray DR, McAlpine B, Washington CV: Acral lentiginous melanoma mimicking benign disease: the Emory experience. J Am Acad Dermatol 2003, 48:183-188.

43. Winslet M, Tejan J: Subungual amelanotic melanoma: a diagnostic pitfall. Postgrad Med J 1990, 66:200-202.

44. Lemon B, Burns R: Malignant melanoma: A literature review and case presentation. J Foot Ankle Surg 1998, 37:48-54.

45. Elmets CA, Ceilley Rl: Amelanotic melanoma presenting as a pyogenic granuloma. Cutis 1980, 25:164-166, 168.

46. Thomson CE, Lang S: Clinical review of an atypical malignant melanoma. Brit J Pod Med 1991, 46:75-77.

47. Bristow I, Metcalfe S: Case report. Acral lentiginous melanoma or diabetic foot ulcer? Diabetic Foot Journal 2008, 11:28-31.
48. Gregson CL, Allain TJ: Amelanotic malignant melanoma disguised as a diabetic foot ulcer. Diabet Med 2004, 21:924-927.

49. Jude E, Dorman S, Kumar S, HBarnett AH: Malignant melanoma masquerading as a diabetic foot ulcer - a case report. Brit J Pod Med 1997, 52:35-36.

50. Kong MF, Jogia R, Jackson S, Quinn M, McNally P, Davies M: Malignant melanoma presenting as a foot ulcer. Lancet 2005, 366:1750.

51. Longobardi JJ: A foot "ulcer" resistant to healing. Acral-lentiginous melanoma. Adv Wound Care 1997, 10:16, 18

52. Rogers LC, Armstrong DG, Boulton AJ, Freemont AJ, Malik RA: Malignant melanoma misdiagnosed as a diabetic foot ulcer. Diabetes Care 2007, 30:444-445.

53. Perks AGB, Miller G, Watson JS: Acral lentignous malignant melanoma in a diabetic foot:a plea for better education. The Foot 1993, 3:83-85.

54. Yesil S, Demir T, Akinci B, Pabuccuoglu U, Ilknur T, Saklamaz A: Amelanotic melanoma misdiagnosed as a diabetic foot ulcer. J Diabetes Complications 2007, 21:335-337.

55. Krige JE, Isaacs S, Hudson DA, King HS, Strover RM, Johnson CA: Delay in the diagnosis of cutaneous malignant melanoma. A prospective study in 250 patients. Cancer 1991, 68:2064-2068.

56. Osborne JE, Bourke JF, Graham-Brown RAC, Hutchinson PE: False negative clinical diagnoses of malignant melanoma. Brit J Dermatol 1999, 140:902-908.

57. Department of Health: Cancer Reform Strategy Book Cancer Reform Strategy (Editor ed.^eds.). City 2007.

58. MacKie RM: Clinical recognition of early invasive malignant melanoma. BMJ 1990, 301:1005-1006

59. National Institute for Health and Clinical Excellence: Referral guidelines for suspected cancer. Book Referral guidelines for suspected cancer (Editor ed. ^eds.) City: Department of Health 2005.

60. Bishop JAN, Corrie PG, Hall PN, Evans J, Gore ME, Kirkham N, Roberts DLL, Anstey AV, Barlow RJ, Cox NH: UK guidelines for the management of cutaneous melanoma. Br J Plast Surg 2002, 55:46-54.

61. Roberts $D$, Anstey $A$, Barlow $R$, Cox N: UK guidelines on the management of cutaneous melanoma. Br J Dermatol 2002, 146:7-17.

62. Australian Cancer Network Melanoma Guidelines Revision Working Party: Clinical Practice Guidelines for the management of melanoma in Australia and New Zealand Wellington: Cancer Council Australia and Australian Cancer Network, Sydney and New Zealand Guidelines Group 2008

63. Albreski D, Sloan SB: Melanoma of the feet: misdiagnosed and misunderstood. Clin Dermatol 2009, 27:556-563.

64. Reviewing and grading the evidence. [http://www.nice.org.uk/niceMedia/ pdf/GDM_Chapter7_0305.pdf].

65. Vandenbroucke JP: In Defense of Case Reports and Case Series. Ann Intern Med 2001, 134:330-334

66. Levit EK, Kagen MH, Scher RK, Grossman M, Altman E: The ABC rule for clinical detection of subungual melanoma. J Am Acad Dermatol 2000, 42:269-274.

doi:10.1186/1757-1146-3-22

Cite this article as: Bristow and de Berker: Development of a practical guide for the early recognition for malignant melanoma of the foot and nail unit. Journal of Foot and Ankle Research 2010 3:22.

\section{Submit your next manuscript to BioMed Central and take full advantage of:}

- Convenient online submission

- Thorough peer review

- No space constraints or color figure charges

- Immediate publication on acceptance

- Inclusion in PubMed, CAS, Scopus and Google Scholar

- Research which is freely available for redistribution 